\title{
Up-regulation of M3-Muscarinic Receptors in Labial Salivary Gland Acini in Primary Sjögren's Syndrome
}

\author{
Dimitra Beroukas, Rhian Goodfellow, Jenny Hiscock, Roland Jonsson, \\ Tom P. Gordon, and Sally A. Waterman
}

Department of Immunology, Allergy and Arthritis (DB, JH, TPG, SAW), Flinders Medical Centre, Bedford Park, Australia; University of Wales College of Medicine (RG), Cardiff, United Kingdom; and Broegelmann Research Laboratory (RJ), University of Bergen, Bergen, Norway

\begin{abstract}
SUMMARY: M3-muscarinic receptors (M3R) mediate parasympathetic cholinergic neurotransmission to salivary and lacrimal glands, and autoantibodies to these receptors have been implicated in sicca symptoms and autonomic dysfunction in Sjögren's syndrome. We have investigated the expression of M3R in paraffin-embedded labial salivary glands (LSG) from seven patients with primary Sjögren's syndrome (pSS) and five healthy controls using high-resolution confocal microscopy and an affinitypurified goat polyclonal antibody raised against the $\mathrm{COOH}$-terminal sequence of the human M3R. Immunolocalization of M3R was similar in control and pSS glands, with punctate staining of M3R in the basal membrane of acinar cells and in the luminal and abluminal membrane of myoepithelial cells. Bright, granular M3R staining was also detected in the cytoplasm and membranes of all intercalated and striated ducts, and infiltrating lymphocytes in pSS. All immunoreactivity was specifically blocked by the immunizing peptide. An increase in M3R expression specifically in acini in pSS was demonstrated by a $30 \%$ increase in receptor number per cluster and a $68 \%$ increase in the number of clusters in the membrane. This up-regulation is consistent with inhibition of parasympathetic neurotransmission, possibly by antagonistic autoantibodies to M3R. The up-regulation, rather than down-regulation, of M3R in acini of pSS LSG can explain the effectiveness of muscarinic agonists in treating sicca symptoms in pSS. (Lab Invest 2002, 82:203-210).
\end{abstract}

S jögren's syndrome (SS) is an autoimmune disease $\mathcal{O}$ of unknown etiology characterized by dry eyes and dry mouth. Recent studies suggest that these symptoms are due to functional inhibition of autonomic neurotransmission to lacrimal and salivary glands, rather than to infiltration and destruction of the glands by $\mathrm{T}$ lymphocytes, because there is a poor correlation between degree of glandular destruction and degree of dysfunction (Jonsson et al, 2001). Functional inhibition of the exocrine glands could reflect a defect in or inhibition of acetylcholine release from the parasympathetic nerves, increased rate of metabolism of acetylcholine in the synaptic junction, a defect in the postjunctional M3-muscarinic acetylcholine receptors (M3R: eg, decreased number or affinity), or a defect in the postjunctional intracellular second messenger systems required for stimulus-secretion coupling.

Two principal animal models have been used to study the pathogenesis of SS: the nonobese diabetic (NOD) mouse and the MLR/lpr mouse (Jonsson and Skarstein, 2001). However these models have provided conflicting results regarding the nature of the functional deficit in the salivary and lacrimal glands. Although there is a decrease in the number of musca-

Received November 15, 2001

Address reprint requests to: Dr. Sally A. Waterman, Department of Immunology, Allergy and Arthritis, School of Medicine, Flinders University, GPO Box 2100, Adelaide SA 5001, Australia. E-mail: Sally.Waterman@finders.edu.au rinic receptors in the salivary glands of the diabetic NOD mouse as determined by ligand-binding studies (Yamamoto et al, 1996), there is up-regulation of intracellular calcium responses in the MRL/lpr lacrimal acinar cells to stimulation by muscarinic and adrenoceptor agonists (Zoukhri et al, 1988b), consistent with denervation hypersensitivity and increased receptor number. In contrast with the up-regulation of intracellular responses in the MRL/lpr mouse, there is a decrease in muscarinic agonist-induced IP3 and CAMP production in the submandibular glands of the NOD mouse (Yamamoto et al, 1996), although IP3 production is increased in the parotid gland (Yamamoto et al, 1996).

These differences highlight the difficulties inherent in using animal models of disease. However, few studies have been performed on human tissue. Dawson et al (2001) demonstrated changes consistent with receptor down-regulation: a decrease in muscarinic receptor sensitivity in salivary acinar cells with no change in the maximal response to muscarinic receptor stimulation. Functional anti-muscarinic receptor antibodies have been demonstrated in the serum of patients with primary Sjögren's syndrome (pSS) and these inhibit parasympathetic neurotransmission (Waterman et al, 2000). Such an inhibition of neurotransmission might be predicted to cause a compensatory up-regulation of M3R number. However, it is not known whether there is any change in the number or distribution of muscarinic receptors in the salivary 
glands of pSS patients. We therefore compared the distribution of M3R in labial salivary gland (LSG) biopsies from patients with pSS with those from healthy controls. We demonstrate, using highresolution confocal microscopy, that M3Rs are upregulated in the acini but not ducts of salivary glands from patients with pSS.

\section{Results}

\section{Immunohistochemical Localization of M3R in Control and pSS LSG}

Conventional fluorescent microscopy was used to study the distribution of M3R in LSG biopsies from healthy human controls and pSS patients. M3R was identified using indirect immunofluorescence. The distribution of M3R was similar in the two groups: M3R was localized in acini and in the epithelia of intercalated and striated ducts. M3R labeling in the acinus was confined to the basal membrane regions and absent from the cytoplasm and nucleus of the secretory cells (Fig. 1, C, D, and E). However, bright M3R fluorescence occurred in the cytoplasm and on the membrane of epithelial cells of both intercalated and striated ducts (Fig. 1, C, D, and E). In salivary glands from pSS, M3R was also localized in the cytoplasm and membranes, but not nuclei of lymphocytes (Fig. 1, $\mathrm{D}$ and E). All immunoreactivity for M3R was specifically blocked by the $\mathrm{COOH}-20$ affinity purified peptide raised against the human epitope (Fig. 1F).

High-resolution confocal microscopy allowed further characterization of the subcellular localization of M3R labeling. Membrane labeling associated with salivary gland acini appeared as beads of discontinuous punctate staining, approximately $0.4 \mu \mathrm{m}$ in size, on the membranes located at the basal regions of the gland (Fig. 2, A and B). The distinctive appearance of M3R labeling in clusters was similar to that observed for other receptors (Coutts et al, 2001; Hansen et al, 1998). Specific localization of the M3R to either the basal membrane of the secretory epithelial cell and/or the myoepithelial cell was difficult to elucidate by conventional fluorescence microscopy because of their close proximity.

\section{Distribution of M3R in Myoepithelial Cells}

Alpha-smooth muscle actin, a cytoplasmic microfilament protein, is present in myoepithelial cells (Skalli et al, 1986) but is not found in glandular epithelial cells. To determine the localization of M3R in myoepithelial versus acinar cells, sections of LSG were therefore double labeled with antibodies to actin and M3R and viewed using high-resolution confocal microscopy. M3R immunoreactivity was present in the membrane both abluminal and luminal to the actin staining (Fig. 3, $A$ and $B$ ), indicating that $M 3 R$ was located within myoepithelial cell membranes. M3R labeling occurring luminal to the actin may indicate that M3R is localized on the basal membrane of the acinar cells as well as in myoepithelial cells (Fig. 3, A and B).

\section{Morphometric Analysis of M3R Expression in pSS}

Confocal microscopy was used to measure the intensity of M3R fluorescence in LSG from normal and pSS biopsy tissue. Because fluorescence intensity is directly related to the number of bound antibodies, and it is likely that the number of antibodies that bind to each receptor is constant given the same receptor configuration, intensity of staining is thus a measure of receptor number. Confocal microscopy allows control over section thickness and the capability to standardize optimal image settings, thereby enabling quantitative studies to be performed.

The M3R clusters on the acinar membrane were analyzed in two ways: the number of receptors within clusters was measured by fluorescent intensity and the number of clusters per unit membrane was measured. The number of receptors per cluster was increased $30 \%$ in pSS (Fig. $4 A ; p=0.0087$ ). The number of clusters of M3R on the acinar cell membranes was increased $68 \%$ in pSS versus control (Fig. 4B and compare Fig. 2, A and B).

Quantitation of M3R intensity in both the membrane and cytoplasm of epithelial cells in the intercalated and striated ducts showed no significant difference between pSS and control tissues (pixel intensity in intercalated ducts $122.4 \pm 9.5$ in pSS and $104.0 \pm$ 17.3 in controls; $n=16,11 ; p=0.09$; pixel intensity in striated ducts $114.0 \pm 17.5$ in pSS and $108.5 \pm 24.5$ in controls; $n=5,5 ; p=0.84$ ). However, the $p$ value of 0.09 for intercalated ducts indicated there was a trend to increased M3R intensity in these regions, suggesting a possible decreasing gradient in the upregulation of $M 3 R$ from the acinus through the intercalated duct to the striated duct.

\section{Discussion}

We have demonstrated that in active pSS, there is up-regulation of surface M3R in the acini of salivary glands. This up-regulation is likely to represent a compensatory mechanism occurring secondary to a reduction in release of acetylcholine from parasympathetic nerves or to a reduction in its postjunctional action. Interestingly, receptor up-regulation occurred specifically in the acini and no significant change in receptor density was detected in the ducts.

\section{Distribution of M3R in Human Salivary Gland}

It is well accepted on the basis of pharmacological studies that M3R mediate the effects of the parasympathetic neurotransmitter, acetylcholine, in stimulating salivary gland secretion. However, the precise cellular and subcellular distribution of this receptor in humans has not been studied. We have demonstrated for the first time that M3R is localized in human myoepithelial cells. These cells have tapering processes that embrace the acini and may assist in salivary flow and provide structural support in the face of increased intraluminal pressure during salivary secretion (Sato et al, 1979). M3R receptors have also been localized to myoepithelial cells in rat lacrimal gland (Lemullois et al, 

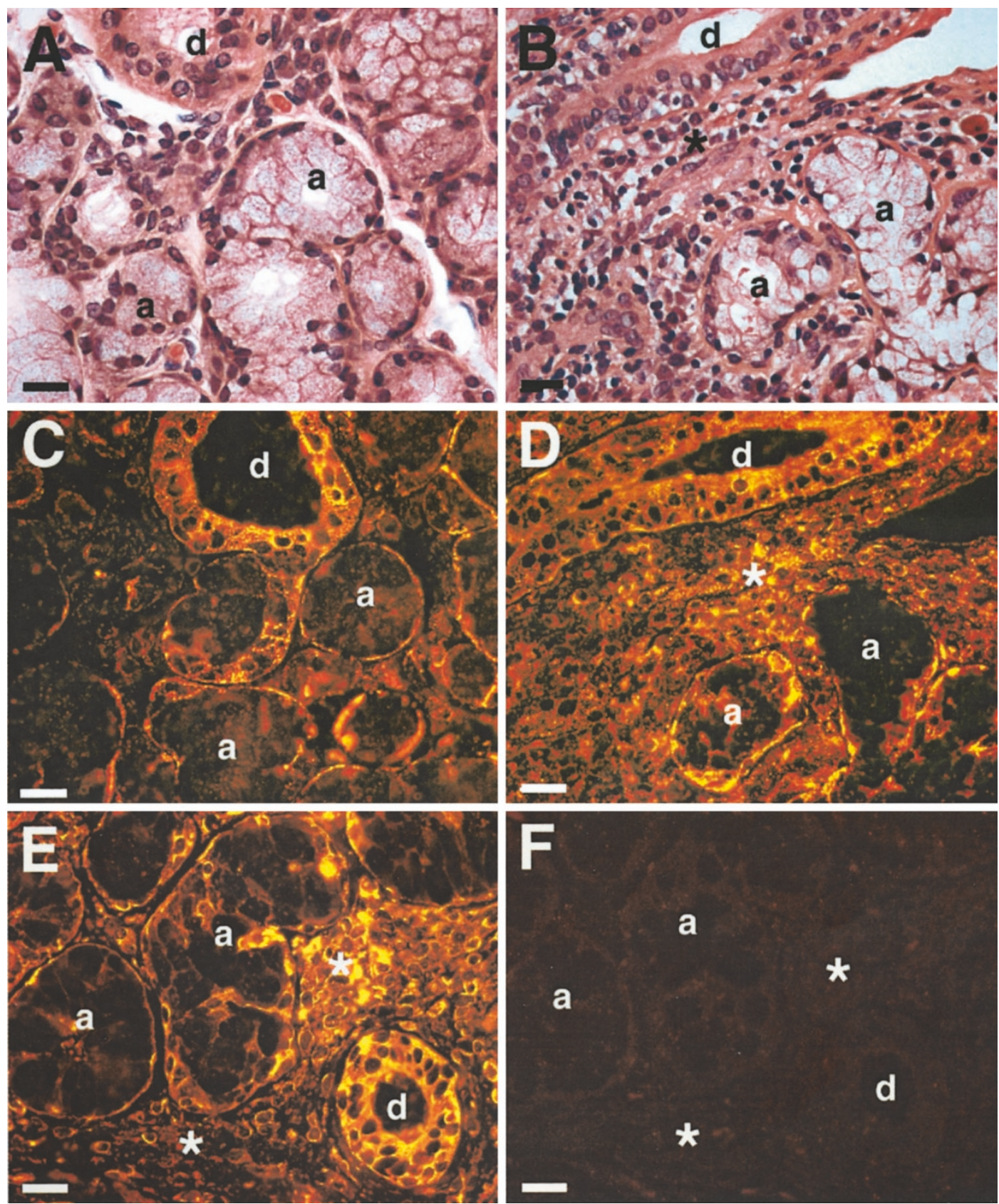

Figure 1.

Immunolocalization of M3-muscarinic receptors (M3R) in labial salivary gland biopsies. Serial sections of biopsy samples were from normal controls (A and C) and a patient with Sjögren's syndrome (B, D, E, and F). A and B were stained with hematoxylin and eosin. C to F were labeled with affinity-purified, polyclonal antibody to human M3R and visualized using fluorescently labeled secondary antibody. $A$ and $C$ and $B$ and D are consecutive. Staining for M3R is present in the basal membrane of acini and in the cytoplasm and membrane of epithelial cells lining the intercalated and striated ducts. In primary Sjögren's syndrome (pSS) tissue, M3R staining was also present in infiltrating lymphocytes. Staining for M3R in pSS was not altered in distribution compared with controls. Immunofluorescent staining was abolished by preabsorption with $100 \mu \mathrm{g} / \mathrm{ml}$ of the human M3R peptide (F). $a=$ acinus, $d=$ duct, ${ }^{*}=$ lymphocytes. Scale bar $=25 \mu \mathrm{m}$.

1996), and stimulation of these receptors causes contraction of the myoepithelial cells (Satoh et al, 1997). The presence of M3R (present study) and aquaporin-1 (Gresz et al, 2001) on salivary gland myoepithelial cells also raises the interesting possibility that some of the effects of acetylcholine on secretion may be mediated indirectly through an action on the myoepithelial cells, rather than a direct effect of acetylcholine on the acinar cells. We have also shown that M3R is likely to be present in the basal membrane of acinar cells, where it would mediate the direct effects of acetylcholine on secretion.

Although the principal effect of parasympathetic nerve stimulation is salivary gland secretion via an action on M3R at the level of the acinus, acetylcholine also acts on epithelial cells in salivary ducts to reduce sodium reabsorption (Young and Cook, 1996). Consistent with this conclusion from functional studies, we found M3R on epithelial cells in the intercalated and striated ducts of both normal and disease LSG. 

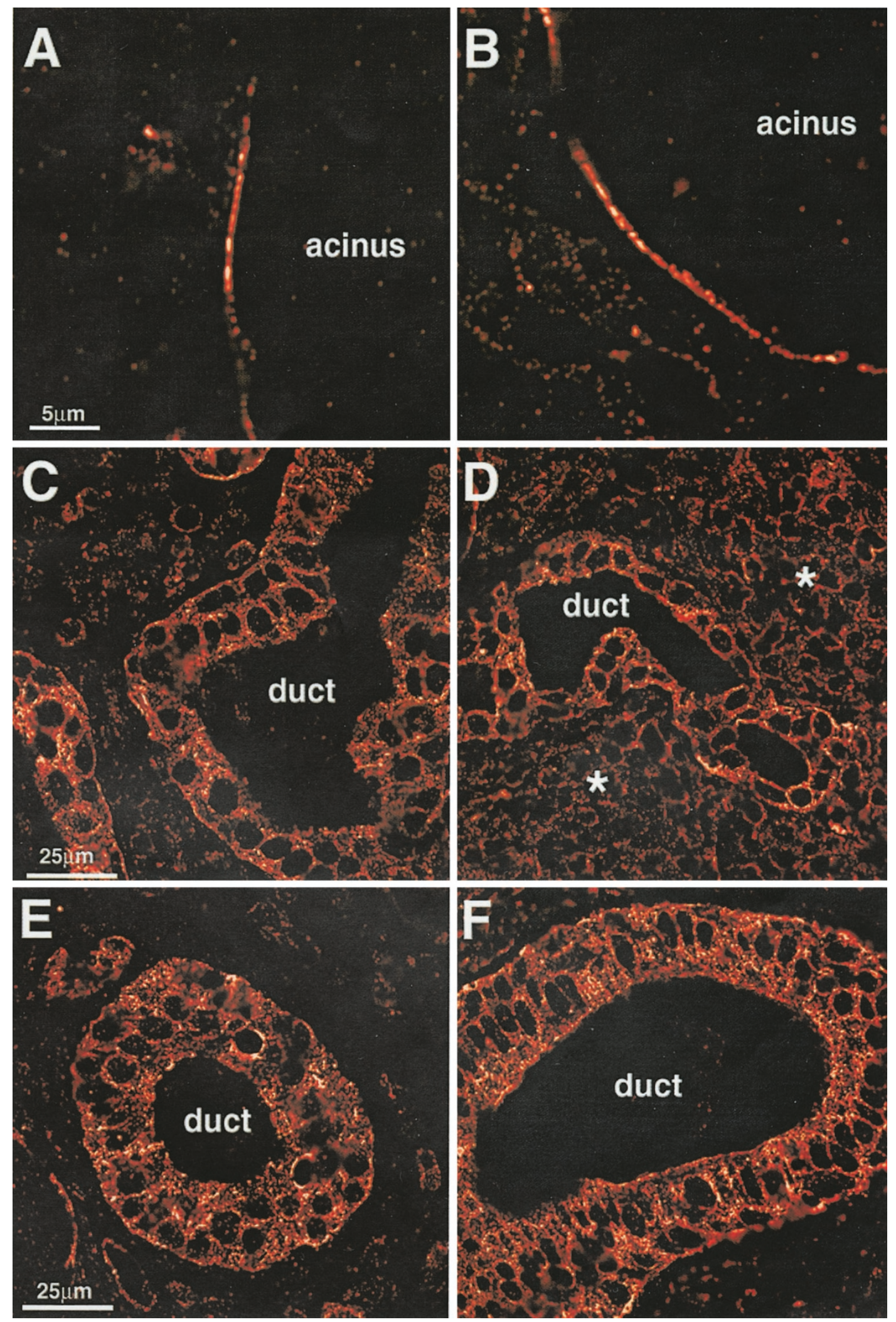

Figure 2.

Confocal microscopy of M3R staining in labial salivary gland (LSG) biopsies from healthy controls (A, C, and E) and patients with pSS (B, D, and F). Confocal images ( $1 \mu \mathrm{m}$ optical thickness) show clusters of M3R immunoreactivity localized to the basal membranes of acinar cells (A and B). No staining is observed in the apical or lateral membranes of the acinar cells, or in the acinar cell cytoplasm or nucleus. M3R immunoreactivity is present in the membrane and cytoplasm of epithelial cells lining intercalated ducts (C and D) and striated ducts ( $E$ and F). Infiltrating lymphocytes in pSS LSG also show M3R immunoreactivity (D). * $=$ lymphocytic infiltrate. 

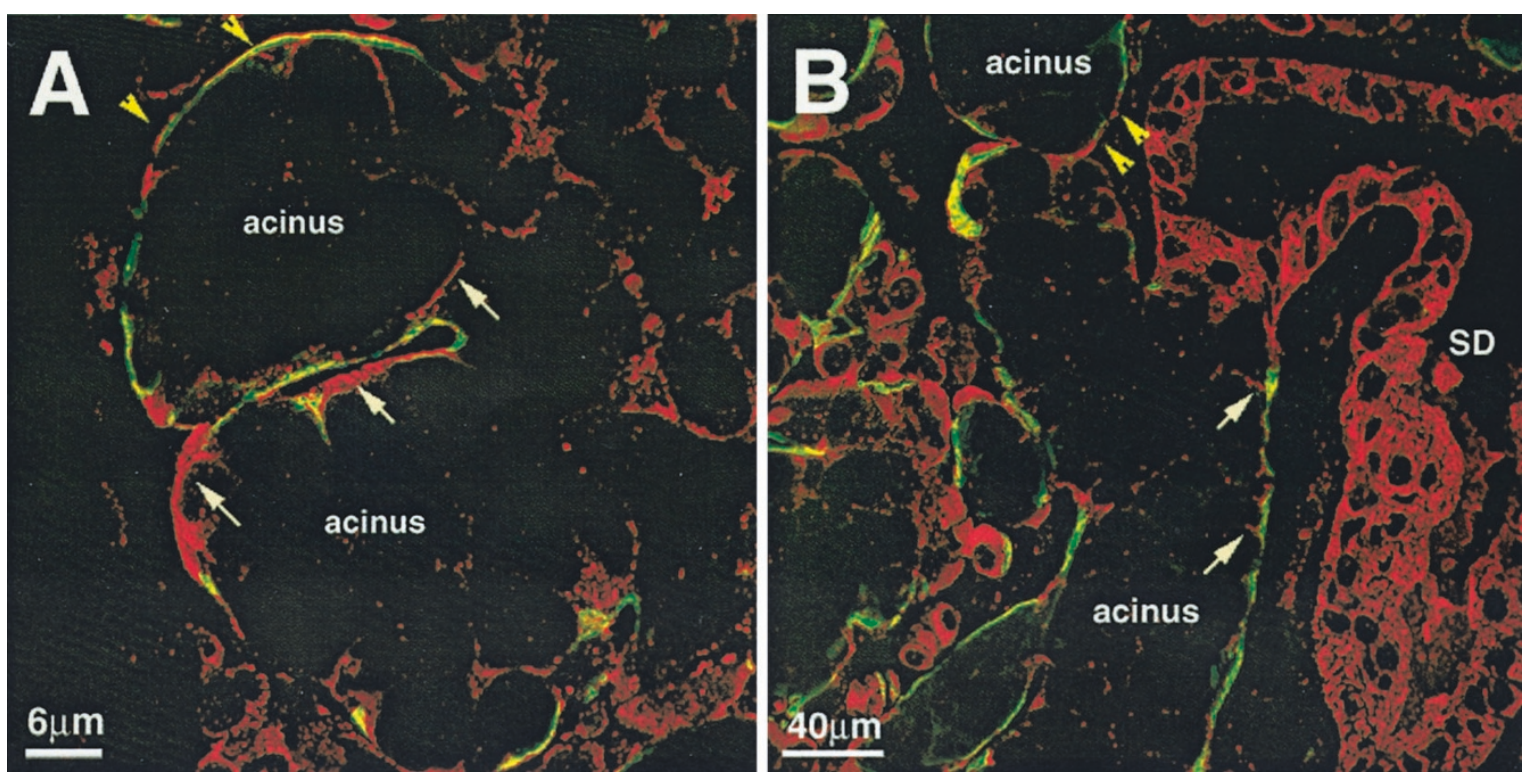

Figure 3.

Dual labeling immunofluorescence of actin filaments in myoepithelial cells (green) and M3R (red). Actin is a marker for myoepithelial cells. Arrows indicate M3R staining that is luminal to the actin and most likely represents staining of the basal membrane of acinar epithelial cells. Immunoreactivity for M3R also occurs abluminally to the actin (arrowheads), indicating that the receptor is present in clusters in the myoepithelial cell membrane. Yellow staining indicates colocalization of M3R and actin. SD = striated duct.

In pSS salivary glands, M3R was present on infiltrating lymphocytes. Previous studies have demonstrated that these cells are principally T cells (Jonsson et al, 2001), and that activation of muscarinic receptors triggers increased intracellular calcium concentrations and increased expression of C-Jun (Kawashima and Fujii, 2000).

\section{Measurement of Receptors and Receptor Cluster Density}

High-resolution confocal microscopy with image analysis demonstrated an increase in both number of clusters of M3R and receptors in each cluster in acini in pSS but not in intercalated or striated ducts. The increase in the number of clusters of receptor in pSS may be explained by a decrease in acinar cell size, although we did not observe an obvious difference in acinar size between control and pSS tissue. However, changes in cell size would not be expected to alter receptor number per cluster. Our results therefore indicate an overall increase in the number of receptors in the gland. This is the first demonstration of changes in M3R receptor number at the cellular level in pSS or animal models. Confocal microscopy has advantages over receptor binding studies and immunoblotting techniques using tissue lysates; these approaches are not able to distinguish precise cellular and subcellular localization of muscarinic receptors in acini and ducts.

\section{Mechanisms Resulting in Receptor Up-regulation}

In human salivary glands, binding of anti-M3R autoantibodies (Nguyen et al 2000; Waterman et al, 2000) would initially be expected to cross-link receptors and trigger internalization and a decrease in receptor num- ber. However to compensate for this short-term change, an increase in receptor density appears to occur (present study). Labial salivary gland biopsy samples used in the present study were from patients who had pSS for 1 to 22 years, and secondary changes would therefore be expected.

Up-regulation of receptors or channels occurs in a variety of tissues as a longer term response to denervation or to blockade of the receptor or channel (eg, Passafaro et al, 1994). Up-regulation of the M3R in pSS LSG could therefore be a response to denervation, decreased acetylcholine release, increased metabolism of acetylcholine by acetylcholinesterase (AChE) in the synaptic cleft (Dawson et al, 2000), or blockade of the muscarinic receptor. Studies in humans and in mouse models have demonstrated that there is no change in the density of innervation of exocrine glands in pSS (Pedersen et al, 2000; Zoukhri et al, 1988a). Recently, a reduction in transmitter release in the MRL/Ipr model has been demonstrated (Zoukhri and Kublin, 2001), but whether this also occurs in humans is unclear. Increased AChE activity and a subsequent inhibition of neurotransmission have been proposed as an important mechanism by Dawson et al (2000), but strong evidence for this has not been published. Inhibition of neurotransmitter release may be caused by cytokines, whose release by lymphocytes and by acinar cells in the exocrine glands is increased in pSS (Boumba et al, 1995; Fox et al, 1994; Grisius et al, 1997). However a study by Dawson et al (2000) indicated that cytokines are unlikely to affect signal transduction directly in acinar cells. There is good evidence that the final alternative, block of the muscarinic receptor, occurs in pSS. Evidence for 
A

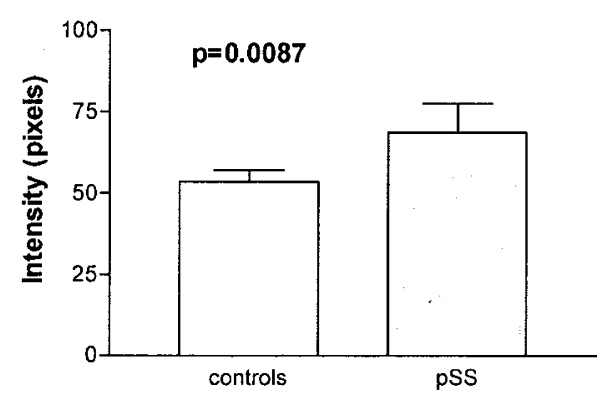

B

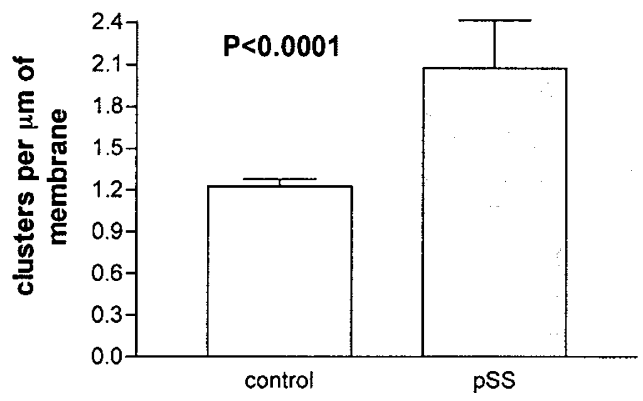

Figure 4.

Quantitation of M3R receptor density and cluster density in control and pSS labial salivary glands. High-resolution confocal microscopy was used to measure the intensity of fluorescent M3R labeling within receptor clusters in acini (A) and the number of receptor clusters per micrometer of acinar membrane acini (B). There was a significant increase both in the number of receptors per cluster in pSS acini compared with controls $(p=0.0087 ; n=$ 5 and 6$)$ and in the density of receptor clusters in the membrane $(p<0.0001$, $n=50$ and 60 ).

anti-M3R antibodies that act postjunctionally to block parasympathetic neurotransmission have recently been demonstrated (Waterman et al, 2000). Similarly in the NOD mouse model of pSS, inhibitory autoantibodies to the M3R have been demonstrated (Nguyen et al, 2000). An interesting and unexpected finding in the present study was that M3R density was increased in acini but not ducts, suggesting that receptor regulation in the ducts differs from that in the acini.

\section{Are the Increased Numbers of M3R Functional?}

Activation of muscarinic receptors results in IP3 synthesis and subsequent increase in cytoplasmic calcium concentration via calcium release from IP3sensitive intracellular stores. Increased cytoplasmic calcium activates $\mathrm{Ca}^{2+}$-dependent $\mathrm{K}^{+}$and $\mathrm{Cl}^{-}$channels and in rat parotid salivary gland, causes a translocation of aquaporin 5 (AQP5) from intracellular vesicles to the apical membrane (Ishikawa et al, 1998). These events in turn allow water excretion to occur. We have recently demonstrated that there is no difference in AQP5 expression in pSS versus control acini (Beroukas et al, 2001), suggesting that the M3 receptors are simply not being activated, are not fully functional, or are not coupled efficiently to intracellular signaling mechanisms. Consistent with the latter pro- posal, Dawson et al (2001) demonstrated using patch clamp electrophysiology and measures of intracellular calcium concentration, a decreased sensitivity of muscarinic receptors in pSS LSG. We suggest that the increased number of M3R in acini are exposed to lower levels of acetylcholine due to blocking autoantibodies and furthermore, even when activated, the subsequent intracellular signaling events are downregulated compared with control. This would be consistent with the unaltered levels of aquaporin- 5 in pSS in spite of increased M3R density (Beroukas et al, 2001).

\section{Therapeutic Implication of Receptor Up-regulation}

The presence of increased receptor numbers on remaining acini in pSS LSG (present study) and the ability of these receptors to respond to stimulation, albeit with reduced sensitivity (Dawson et al, 2001), provide a scientific explanation for the clinical observation that patients with pSS respond to treatment with muscarinic receptor agonists, such as pilocarpine and cevimeline, in spite of glandular destruction.

In conclusion, we have demonstrated that M3muscarinic receptors are up-regulated in acini of salivary glands from patients with primary Sjögren's syndrome. This is likely to be a compensatory effect, occurring in response to inhibition of transmitter release by cytokines and/or blockade of muscarinic receptors by $\mathrm{M} 3 \mathrm{R}$ autoantibodies. The differences between our results and those obtained in animal studies reinforce the importance of performing studies using human tissue.

\section{Materials and Methods}

\section{Human Tissues}

LSG tissue was obtained by labial biopsy from seven patients (mean age, $51 \pm 12$ years) who fulfilled the European consensus criteria for the diagnosis of pSS, including seropositivity for anti-Ro/La antibodies, unstimulated salivary flow less than $1.5 \mathrm{ml}$ per $15 \mathrm{~min}-$ utes, and LSG biopsy focus scores of higher than 1 per $4 \mathrm{~mm}^{2}$. Disease duration ranged from 1 to 22 years. Biopsy tissues were obtained from five healthy controls (mean age, $41 \pm 9$ years; unstimulated salivary flow, $4.7 \pm 2 \mathrm{ml}$ per 15 minutes). Control LSG tissues were histologically normal, with no foci of lymphocytes.

\section{Immunohistochemical Localization on Paraffin-Embedded Tissue}

Paraffin blocks were retrieved from routine files at the Flinders Medical Centre and indirect immunofluorescence was used to detect the expression of the M3R in LSG. A random 4- $\mu$ m-thick section was cut for each case and dried onto histogrip-coated slides overnight at $57^{\circ} \mathrm{C}$. The sections were deparaffinized, microwaved for 10 minutes (Toshiba microwave at $1000 \mathrm{~W}$ using the microwave antigen-retrieval method of Shi et al (1991), blocked with neat PBS (PBS-F; DAKO Corporation, Carpinteria, California), and incubated with a 
previously characterized goat polyclonal antibody raised against the 20 amino acid $\mathrm{COOH}$-terminus of the human muscarinic acetylcholine receptor (M3RC20; 1:50, Santa-Cruz Biochemicals, Santa Cruz, California). Sections were then washed with $0.1 \%$ Tween 20 in Tris buffered saline pH 7.4 (TBS) and the antibody binding was visualized using a donkey anti-goat $\operatorname{lgG}$ conjugated to indocarbocyanin fluorophore, (Cy-3, Jackson Immunoresearch, West Grove, Pennsylvania; 1:100 dilution for 2 hours at room temperature), washed and mounted in 1,4 diazabicyclo-(222)octane, phospho-glycerol. For dual labeling studies, sections were incubated with M3R antibody together with a mouse monoclonal antibody raised against the human anti-smooth muscle actin (1:100; Maxim Biotech, San Francisco, California). The actin smooth muscle antibody was visualized using a donkey antimouse FITC (1:100; Jackson). Consecutive sections from each tissue block were stained with Mayer's hematoxylin and eosin for histologic examination. Sections were viewed using the Leica DMLBfluorescent microscope and images were captured using a Leica DC200 digital camera. Digital images were processed to match contrast and brightness, and assembled into panels using Adobe PhotoShop v5.5.

\section{Controls}

The specificity of the primary antibody staining was determined by (1) omission of primary antibody from incubations, (2) preabsorption with immunizing peptide, and (3) preabsorption with unrelated peptide, calreticulin, at $100 \mu \mathrm{g} / \mathrm{ml}$. The primary antibody was preabsorbed with $100 \mu \mathrm{g} / \mathrm{ml}$ of the M3R-C20 peptide (Santa Cruz), overnight at $4^{\circ} \mathrm{C}$ before applying to the sections.

\section{Confocal Microscopy}

Random sections were viewed in an Olympus AX70 microscope attached to a BioRad 1024 scanning confocal system equipped with a helium neon (543 $\mathrm{nm})$ laser and argon (488 $\mathrm{nm}$ ) laser for excitation and detection of CY3 and FITC respectively. The confocal settings for capturing images were obtained from the sample with the brightest fluorescence; the samples had been coded to ensure unbiased collection of data. Images of acini were collected according to the following procedure. Confocal settings were optimized with regard to saturation and were laser power $1 \%$, iris 2.0, gain 915 , and $100 \times$ objective lens with software zoom of 3.5. Ten fields $(31.2 \times 31.2 \mu \mathrm{m})$ were captured from each sample. The position of the first field was chosen at random and subsequent fields were chosen systematically in a $100-\mu \mathrm{m}$ grid pattern and two regions of gland were sampled, five fields from each area. The grid interval of $100 \mu \mathrm{m}$ allowed each new field to sample a new acinus.

Images for the analysis of M3R immunofluorescence in intercalated and striated ducts were collected differently than those of acini, in accordance with the different frequency of occurrence and distribution of M3R. Three intercalated and one striated duct were selected at random in each sample and a series of optical sections was collected at $0.4-\mu \mathrm{m}$ intervals through each duct. Images were collected using $60 \times$ objective lens (NA 1.4) and zoom of 3 with other confocal settings the same as for the acini. All images were collected at the same confocal settings.

\section{Quantitation of Fluorescent Intensity}

The average intensity of the fluorescent labeling for of M3R clusters located in the membrane at the base of the acini was determined using the BioRad Lasersharp image analysis program (BioRad, Hemel Hempstead, United Kingdom). Two measures were taken to ensure that our quantitation was unbiased: measurements were made by an investigator blinded to the nature of the coded LSG sample and then measurements were made systematically at 80 locations determined by a $100-\mu \mathrm{m}$ grid. Measurements were made every $2.2 \mu \mathrm{m}$ along the basal membrane region of acini. Clusters of M3R occurring at these points were circumscribed with the mouse, and the intensity of fluorescence was measured as pixel intensity (PI). Six to 10 clusters were sampled in each of the 10 fields. A further three areas were outlined in regions without fluorescent labeling to determine the average intensity of the background. These background measurements were averaged and then subtracted from each measurement of M3R fluorescence to provide a measure of absolute fluorescent intensity. Values were averaged per field giving a total of 60 to 80 measurements of membrane fluorescent intensity per sample (patient or control). In addition, the number of receptor clusters in the acinar membrane was counted using NIH Image v1.61 and expressed relative to the length of membrane. At least 30 receptor clusters were measured for each image.

In ducts, a grid with squares of $1.5 \mu \mathrm{m}$ was placed over a representative optical section from each z-section. M3R fluorescent intensity was measured where the clusters intersected two sides of the grid, proceeding systematically across the section. The intensity of immunofluorescence was measured for 30 clusters per duct. Ninety measurements were therefore acquired of intercalated ducts and 30 of the striated ducts per sample. Measurements of background were taken at three locations where no fluorescence could be seen and the mean value of these was subtracted from each measurement of an M3R cluster.

\section{Statistical Analysis}

Results were expressed as mean fluorescent intensity \pm SEM. Differences in fluorescent intensity and number of clusters between healthy control and pSS samples were analyzed using Mann-Whitney U-tests. $P$ values of $<0.05$ were considered significant.

\section{Acknowledgements}

This study was funded by grants from the National Health and Medical Research Council (NH\&MRC) to TPG and to SAW. SAW is an NH\&MRC R. D. Wright 
Fellow. The antibody to smooth muscle actin was a gift from Dr. B. Gannon, Department of Anatomy and Histology, Flinders University of South Australia. We also thank Dr. Luke Dawson for helpful discussions. TG and RJ would like to acknowledge the late Prof. Michael Humphreys-Beher for inspiring discussions and friendship.

\section{References}

Beroukas D, Hiscock J, Jonsson R, Waterman SA, and Gordon TP (2001). Subcellular distribution of aquaporin-5 in salivary glands in primary Sjögren's Syndrome. The Lancet 358:1875-1876.

Boumba D, Skopouli FN, and Moutsopoulos HM (1995). Cytokine mRNA expression in labial salivary gland tissues from patients with primary Sjögren's syndrome. Br J Rheumatol 34:326-333.

Coutts AA, Anavi-Goffer S, Ross RA, MacEwan DJ, Mackie K, Pertwee RG, and Irving AJ (2001). Agonist-induced internalization and trafficking of cannabinoid $\mathrm{CB} 1$ receptors in hippocampal neurons. J Neurosci 21:2425-33.

Dawson LJ, Christmas SE, and Smith PM (2000). An investigation of interactions between the immune system and stimulus-secretion coupling in mouse submandibular acinar cells: A possible mechanism to account for reduced salivary flow rates associated with the onset of Sjögren's syndrome. Rheumatology 39:1226-1233.

Dawson LJ, Field EA, Harmer AH, and Smith PM (2001). Acetylcholine-evoked calcium mobilisation and ion channel activation in human labial salivary gland acinar cells from patients with primary Sjögren's syndrome. Clin Exp Immunol 123:1-7.

Fox RI, Kang HI, Ando D, Abrams J, and Pisa E (1994). Cytokine mRNA expression in salivary gland biopsies of Sjögren's syndrome. J Immunol 152:5532-5539.

Gresz V, Kwon TH, Hurley PT, Varga G, Zeles T, Nielsen S, Case RM and Steward MC (2001). Identification and localization of aquaporin water channels in human salivary glands. Am J Physiol 281:G247-G254.

Grisius MM, Bermusez DK, and Fox PC (1997). Salivary and serum interleukin 6 in primary Sjögren's syndrome. J Rheumatol 24:1089-1091.

Hansen MA, Balcar VJ, Barden JA, and Bennett MR (1998). The distribution of single P2x1-receptor clusters on smooth muscle cells in relation to nerve varicosities in the rat urinary bladder. J Neurocytol 27:529-39.

Ishikawa Y, Eguchi T, Skowronski T, and Ishida H (1998). Acetylcholine acts on M3 muscarinic receptors and induces the translocation of aquaporin5 water channel via cytosolic $\mathrm{Ca}^{2+}$ elevation in rat parotid glands. Biochem Biophys Res Commun 245:835-840.

Jonsson R, Haga H-J, and Gordon T (2001). Sjögren's Syndrome. In: Koopman WJ, editor. Arthritis and allied conditions: A textbook of rheumatology, 14th ed. Philadelphia: Lippincott Williams \& Wilkins: 1736-1759.

Jonsson R and Skarstein K (2001). Experimental models of Sjögren's Syndrome. In: Theofilopoulos AN and Bona CA, editors. The molecular pathology of autoimmune diseases. Chur: Harwood Academic Press: in press.
Kawashima K and Fujii T (2000). Extraneuronal cholinergic system in lymphocytes. Pharmacol Ther 86:29-48.

Lemullois M, Rossignol B, and Mauduit P (1996). Immunolocalization of myoepithelial cells in isolated acini of rat exorbital lacrimal gland: Cellular distribution of muscarinic receptors. Biol Cell 86:175-181.

Nguyen K-HT, Brayer J, Cha S, Diggs S, Yasunari U, Hilal G, Peck $A B$, and Humphreys-Beher MG (2000). Evidence for antimuscarinic acetylcholine receptor antibody-mediated secretory dysfunction in NOD mice. Arthritis Rheum 43:2297-2306.

Passafaro M, Clementi F, Pollo A, Carbone E, and Sher E (1994). $\omega$-Conotoxin and $\mathrm{Cd}^{2+}$ stimulate the recruitment to the plasma membrane of an intracellular pool of voltageoperated $\mathrm{Ca}^{2+}$ channels. Neuron 12:317-326.

Pedersen AM, Dissing S, Fahrenkrug J, Hannibal J, Reibel J, and Nauntofte B (2000). Innervation pattern and $\mathrm{Ca}^{2+}$ signalling in labial salivary glands of healthy individuals and patients with primary Sjögren's syndrome (pSS). J Oral Pathol Med 29:97-109.

Sato K, Nishiyama A, and Kobayashi M (1979). Mechanical properties and functions of the myoepithelium in the eccrine sweat gland. Am J Physiol 6:C177-C184.

Satoh Y, Sano K, Habara Y, and Kanno T (1997). Effects of carbachol and catecholamines on ultrastructure and intracellular calcium-ion dynamics of acinar and myoepithelial cells of lacrimal glands. Cell Tissue Res 289:473-485.

Shi SR, Key ME, and Kalra KL (1991). Antigen retrieval in formalin-fixed, paraffin-embedded tissues: An enhancement method for immunohistochemical staining based on microwave oven heating of tissue sections. J Histochem Cytochem 39:741-748.

Skalli O, Ropraz P, Trzeciak A, Benzonana G, Gillessen D, and Gabbiani $G$ (1986). A monoclonal antibody against alpha-smooth muscle actin: A new probe for smooth muscle differentiation. J Cell Biol 103:2787-2796.

Waterman SA, Gordon TP, and Rischmueller R (2000). Inhibitory effects of muscarinic receptor autoantibodies on parasympathetic neurotransmission in Sjögren's syndrome. Arthritis Rheum 43:1647-1654.

Yamamoto H, Sims NE, Macauley SP, Nguyen K-HT, Nakagawa $Y$, and Humphreys-Beher M (1996). Alterations in the secretory response of non-obese diabetic (NOD) mice to muscarinic receptor stimulation. Clin Immunol Immunopathol 78:245-255.

Young JA, and Cook DI (1996). The major salivary glands. In: Greger R and Windhorst U, editors. Comprehensive human physiology. Berlin: Springer-Verlag, 1996: 1309-1326.

Zoukhri D, Hodges RR, and Dartt DA (1988a). Lacrimal gland innervation is not altered with the onset and progression of disease in a murine model of Sjögren's syndrome. Clin Immunol Immunopathol 89:126-133.

Zoukhri D, Hodges RR, Rawe IM, and Dartt DA (1988b). Ca ${ }^{2+}$ signalling by cholinergic and $\alpha_{1}$-adrenergic agonists is upregulated in lacrimal and submandibular glands in a murine model of Sjögren's syndrome. Clin Immunol Immunopathol 89:134-140.

Zoukhri D and Kublin CL (2001). Impaired neurotransmitter release from lacrimal and salivary gland nerves of a murine model of Sjögren's syndrome. Invest Ophthalmol Vis Sci 42:925-932. 